La impronta autoficcional.

$(\mathrm{Re})$ fracciones del yo

en la narrativa argentina contemporánea

José Manuel González Álvarez (ed.) 


\title{
Estudios Latinoamericanos
}

\author{
DIRECCIÓN \\ Walther L. Bernecker \\ Sabine Friedrich \\ Gian Luca Gardini \\ Silke Jansen \\ Andrea Pagni
}

\section{CONSEJO CIENTÍFICO}

\author{
Anke Birkenmaier (Indiana University, Bloomington) \\ Sean Burges (Australian National University) \\ Ana Casas (Universidad de Alcalá) \\ Clara Eugenia Lida (El Colegio de México) \\ Ilse Logie (Universiteit Gent) \\ Andrés Malamud (Universidade de Lisboa) \\ Ana Peluffo (University of California, Davis) \\ Juan Valdez (Mills College, Auckland) \\ José del Valle (City University of New York, CUNY)
}

Vol. 55 
José Manuel González Álvarez (ed.)

La impronta autoficcional. (Re)fracciones del yo

en la narrativa argentina contemporánea

IBEROAMERICANA - VERVUERT - 20 I 8 
Redacción:

FAU Erlangen-Nürnberg

Centro de Estudios de Área

Sección Iberoamérica

Bismarckstr. 1

D-91054 Erlangen

Alemania

Este libro se publicó gracias al apoyo financiero otorgado por la Fundación Alexander von Humboldt

Unterstützt von / Supported by

Alexander von Humboldt

Stiftung / Foundation

Cualquier forma de reproducción, distribución, comunicación pública o transformación

de esta obra solo puede ser realizada con la autorización de sus titulares, salvo excepción prevista

por la ley. Diríjase a CEDRO (Centro Español de Derechos Reprográficos)

si necesita fotocopiar o escanear algún fragmento de esta obra

(www.conlicencia.com; 917021970 / 9327204 47).

(C) Iberoamericana, 2018

Amor de Dios, 1 - E-28014 Madrid

Tel.: +34914293522

Fax: +34914295397

info@iberoamericanalibros.com

www.iberoamericana-vervuert.es

(C) Vervuert, 2018

Elisabethenstr. 3-9 - D-60594 Frankfurt am Main

Tel.: +49695974617

Fax: +49695978743

info@iberoamericanalibros.com

www.iberoamericana-vervuert.es

ISBN 978-84-8489-379-0 (Iberoamericana)

ISBN 978-3-95487-751-5 (Vervuert)

ISBN 978-3-95487-752-2 (eBook)

Depósito Legal: M-10522-2018

Diseño de cubierta: a. f. diseño y comunicación

Impreso en España

The paper on which this book is printed meets the requirements of ISO 9706 